\title{
Kinetics of creatine ingested as a food ingredient
}

\author{
Louise Deldicque · Jacques Décombaz • \\ Hermann Zbinden Foncea · Jacques Vuichoud • \\ Jacques R. Poortmans · Marc Francaux
}

Accepted: 16 August 2007/Published online: 13 September 2007

(C) Springer-Verlag 2007

\begin{abstract}
The aim of the present study was to test if the consumption of creatine incorporated in food bars modifies creatine plasma kinetics, erythrocyte retention and loss in urine and in feces when compared with its consumption in the form of an aqueous solution (AS). Seventeen healthy young men ingested $2 \mathrm{~g}$ creatine either in the form of AS, or incorporated in a protein (PP)- or in a beta-glucan (BG)-rich food bar. Kinetics of plasma creatine was measured for 8 -h duration and urinary excretion for $24 \mathrm{~h}$. Then, the subjects received the same treatment thrice a day for 1 week at the end of which creatine contents were determined in erythrocytes and in feces ( $n=4$ for feces). The three crossover treatments were interspaced by a $40 \pm 1.2$-day wash-out. Absorption of creatine was slowed down by 8 -fold in the presence of BG $(P<0.001)$ and by 4 -fold with PP $(P<0.001)$ whereas the velocity rate constant of elimination and the area under the curve were not modified. Urinary loss of creatine in the first $24 \mathrm{~h}$ following ingestion was $15 \pm 1.9 \%$ in AS and $14 \pm 2.2 \%$ in PP conditions (NS), whereas it was only $8 \pm 1.2 \%$ with BG $(P=0.004)$. Increase in creatine concentration in erythrocyte was
\end{abstract}

L. Deldicque $\cdot$ H. Zbinden Foncea $\cdot$ M. Francaux $(\bowtie)$ Institut d'Education physique et de Réadaptation, Faculté de Médecine, Université catholique de Louvain, Place Pierre de Coubertin 1, 1348 Louvain-la-Neuve, Belgium e-mail:marc.francaux@uclouvain.be

J. Décombaz · J. Vuichoud

Nestlé Research Center, 1000,

Lausanne 26, Switzerland

J. R. Poortmans

Institut des Sciences de la Motricité,

Université Libre de Bruxelles, Avenue Paul Héger 28,

1000 Bruxelles, Belgium similar in whatever form the creatine was ingested. Creatine seems to be totally absorbed since no creatine or creatinine was detectable in feces. No side effects were reported. In conclusion, ingestion of creatine combined with BG facilitates its retention by slowing down its absorption rate and reducing its urinary excretion.

Keywords Creatinine - Erythrocytes - Feces · Pharmacokinetics · Beta-glucan

\section{Introduction}

Since the paper of Harris et al. (1992), creatine has become one of the most popular dietary supplements in the world. In 2000, the American College of Sports Medicine estimated that 2,500 metric tons were consumed every year (Terjung et al. 2000). Creatine improves sport performance during repeated short-duration/high-intensity exercises (Balsom et al. 1995) and amplifies the increase in lean body mass and strength induced by resistance training (Kreider et al. 1998). Creatine has also therapeutic benefits, it accelerates skeletal muscle recovery after prolonged immobilization (Hespel et al. 2001) and it slows down muscle wasting in certain myopathies (Louis et al. 2003; Tarnopolsky et al. 2004). Furthermore, more recent but limited information indicates that creatine may improve cognitive performance (McMorris et al. 2007).

Two strategies of supplementation exist. In most conditions, $20 \mathrm{~g}$ creatine is ingested every day for 5 days, increasing its muscle content by about 20\% (Deldicque et al. 2005; Greenhaff et al. 1994). Thereafter, 3-5 g are consumed daily to maintain its muscle uptake (Hultman et al. 1996). A second strategy omits the loading phase. In this case, the rise in muscle creatine content is slower, but 
reaches the same level after about 15 days (Hultman et al. 1996). Other cell types, such as erythrocytes and neurons, also store creatine during supplementation (Dechent et al. 1999; Preen et al. 2005). Nevertheless, the level of accumulation is not necessarily correlated between tissues (Preen et al. 2005).

A large fraction of the ingested creatine is excreted in urine, from 33 to $77 \%$ of the original dose ranging from 8 to $21 \mathrm{~g} /$ day during 1-14 days (Poortmans and Francaux 2007). This might potentially induce a kidney overload. A few renal impairments have been reported (Koshy et al. 1999; Pritchard and Kalra 1998), although cohort studies have not revealed any deleterious effects on renal functions (Francaux and Poortmans 2006). Recently, increased excretion of methylamine and formaldehyde, have been observed after ingestion of large amounts of creatine $(21 \mathrm{~g} /$ day $)$ for 2 weeks (Poortmans et al. 2005). Although the level of these two mutagenic agents remained within the normal range for a healthy population, the development of strategies using low doses of creatine is wanted for reducing the potential risks induced by supplementation with larger amounts. These strategies should lead to a better retention of creatine by the body and thus, to a lower urinary excretion.

One of the most obvious ways to reach this goal is to slow down the velocity of intestinal absorption of creatine by adding fibers to the bolus. Beta-glucans are structural polysaccharides present as dietary fibers in barley and oat grains. Their water-soluble properties as well as their chemical structure help to increase the viscosity of foods. Beta-glucans are known to reduce the rate of carbohydrate and lipid absorption (Lifschitz et al. 2002; Wursch and Pi-Sunyer 1997). The first hypothesis of the present study is that beta-glucans consumed with creatine could slow down the rate of absorption of the latter and consequently favour its retention by the body.

Athletes often combine creatine with protein supplements expecting an enhancement of protein synthesis through a higher amino acid availability. The presence of food, other than fibers, within the gastrointestinal tract markedly changes the velocity of absorption of drugs and dietary substances and potentially alters their bioavailability (Welling 1977). Therefore, our second hypothesis is that the rate of creatine absorption would also be slowed down when combined with the ingestion of solid foods, amongst others food eaten by athletes.

Little is known on the bioavailability of creatine ingested as a dietary supplement. Otto Folin (1906) was unable to find any trace of creatine in the feces and Chanutin (1926) suggested that creatine is completely absorbed by the intestinal tract.

In the present study, we tested if the consumption of creatine incorporated in food bars rich in beta-glucans or in proteins, could modify creatine plasma kinetics, erythrocyte retention and loss in urine and in feces when compared to its supplementation in aqueous solution (AS).

\section{Materials and methods}

\section{Subjects}

Seventeen healthy males $(21 \pm 0.3$ years, $179 \pm 1.0 \mathrm{~cm}$, $71 \pm 2.9 \mathrm{~kg}$, mean \pm SEM) were recruited. They were physically active, although none of them was a high-level athlete. They were instructed to keep their diet and their physical activity unchanged during the experiment. Food intake was recorded for 7 days, prior to the beginning of the experiment, by means of a standardized questionnaire and computed using the Nutrilog software (Marans, France). Daily energy intake was $2447 \pm 111.7 \mathrm{kcal}$ divided into $48 \pm 1.1 \%$ carbohydrates, $34 \pm 1.1 \%$ lipids, $3 \pm 0.8 \%$ alcohol and $15 \pm 1.1 \%$ proteins which correspond to $1.3 \pm 0.10 \mathrm{~g}$ of proteins per kg body mass. The subjects did not consume any food supplement for at least 2 months and they did not take any drug on a regular basis. They were given an oral and written account of the study before signing an informed consent document. This study was approved by the Ethic Committee of the Université catholique de Louvain and all the procedures used were in accordance with the Declaration of Helsinki.

\section{Protocol}

The subjects received randomly three treatments, which were interspaced by a wash-out period of $40 \pm 1.2$ days, with a range between 29 and 57 days. This duration was chosen because a period of $28 \mathrm{~d}$ without creatine was reported to be sufficient to restore intramuscular creatine level to basal concentrations (Febbraio et al. 1995). One treatment consisted in $2 \mathrm{~g}$ creatine powder ( $2.3 \mathrm{~g}$ creatine monohydrate, food grade, Creapure ${ }^{\mathrm{TM}}$ ), consumed in $150 \mathrm{ml}$ of AS. The two others were food bars with commercial recipes manufactured for the study by the Nestlé Product Technology Center PTC-Orbe, Switzerland: one was a protein-rich bar (PP) and the other one was a betaglucan-rich bar (BG). The protocol is summarized in Fig. 1 .

The BG-bar contained $16.7 \mathrm{~g}$ carbohydrates, $4.1 \mathrm{~g}$ proteins, $2.3 \mathrm{~g}$ lipids and $3.2 \mathrm{~g}$ fibers ( $\sim 1.5 \mathrm{~g}$ beta-glucans) and a total energy content of $104 \mathrm{kcal}$. The PP-bar contained $19.0 \mathrm{~g}$ carbohydrates, $14.3 \mathrm{~g}$ proteins, $1.3 \mathrm{~g}$ lipids and $0.1 \mathrm{~g}$ fibers and a total energy content of $144 \mathrm{kcal}$. Both bars also contained $2 \mathrm{~g}$ of creatine, as checked by subsequent analysis, incorporated as monohydrate at manufacture.

The day before the experiment, the subjects received standardized meals and were asked to collect their $24 \mathrm{~h}$ urine 


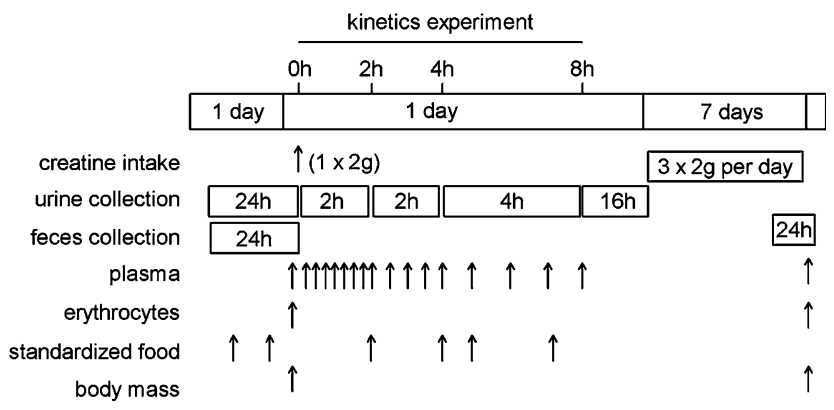

Fig. 1 Experimental protocol

production. Following an overnight fast, they arrived at 7.00 a.m. in the laboratory and were weighed. They filled in a binary (yes/no) questionnaire assessing the occurrence of adverse symptoms over the past 7 days (stomachache, diarrhea, constipation, nausea, headache, dizzy spell, blackout, pounding, insomnia, tendonitis, cramps, muscle soreness, fatigue, loss of appetite, hunger and other complaints). A catheter was introduced into an antecubital vein and a first blood sample was drawn to determine the basal level of creatine and creatinine in plasma and erythrocytes. Then, the subjects ingested one of the three creatine products (AS, BG or PP) and 16 blood samples were further taken up during the next $8 \mathrm{~h}$ to determine the plasma kinetics of creatine and creatinine. A standardized breakfast, snack, lunch and a last snack were given, respectively, 2, 4, 5 and $7 \mathrm{~h}$ after creatine ingestion. Similarly, urines were collected 2, 4, 8 and $24 \mathrm{~h}$ after creatine ingestion. The subjects were instructed to consume the test product thrice a day, in the morning, at noon and in the evening, for the next 7 days. On day 8 , the subjects returned to the laboratory after an overnight fast. They were weighed again and a blood sample was drawn for plasma and erythrocyte creatine and creatinine determination. The health status questionnaire was filled in again. Four of the subjects collected their 24 -h feces six times on the day before and the last day of each supplementation period.

\section{Procedures}

Venous blood was collected on heparin as an anticoagulent. The tubes were placed immediately on ice and centrifugated at $3,000 \mathrm{~g}$ for $6 \mathrm{~min}$ at $4^{\circ} \mathrm{C}$. Plasma $(900 \mu \mathrm{l})$ was deproteinized with sulfosalicylic acid 5\% (300 $\mu \mathrm{l})$ and centrifugated again at $3,000 \mathrm{~g}$ for $6 \mathrm{~min}$. $\mathrm{NaOH} 0.1 \mathrm{M}$ $(90 \mu \mathrm{l})$ was added to supernatant $(300 \mu \mathrm{l})$ to obtain a $\mathrm{pH}$ value of about 7.8. Samples were stored at $-20^{\circ} \mathrm{C}$.

After the first centrifugation, erythrocytes were washed twice with a similar volume of physiological water $(0.9 \%$ $\mathrm{NaCl}$, centrifugation $1,000 \mathrm{~g}, 5 \mathrm{~min}, 4^{\circ} \mathrm{C}$ ). After three frozen and defrozen procedures, erythrocytes $(300 \mu \mathrm{l})$ were deproteinized with sulfosalicylic acid 5\% (600 $\mu$ l) and then centrifugated at $3,000 \mathrm{~g}$ during $6 \mathrm{~min}$. Supernatant was collected and centrifugated again. The clear supernatant was neutralized with $\mathrm{NaOH} 0.1 \mathrm{M}$.

Urines were collected in a plastic bottle and the volume was measured. An aliquot $(10 \mathrm{ml})$ was stored at $-20^{\circ} \mathrm{C}$.

Creatine and creatinine content in plasma, erythrocytes and urine were analyzed by spectrophotometry by enzymatic technique (Siedel et al. 1984), omitting creatininase for creatine determination. Creatine and creatinine content in test bars were determined by HPLC following homogeneization and solvent extraction according to a modified method of Dash and Sawhney (2002).

The 24-h collection of feces was placed in a plastic box and weighed. An aliquot was stored at $-80^{\circ} \mathrm{C}$. Due to the large bacterial content, the feces were prepared as soon as possible, avoiding the acidic deprotenization step that might induce a degradation of creatine to creatinine (Ganguly et al. 2003).

Both creatine and creatinine content in feces was analyzed by HPLC at $205 \mathrm{~nm}$. After dilution of a feces aliquot in $0.045 \mathrm{M}$ ammonium sulfate containing an internal standard (4-[2-aminoethyl]-benzene sulfonamide), the sample was filtered on a $10 \mathrm{kDa}$. The following conditions were used to identify creatine: 2 Beckman RP-C18 Ultrasphere ODS columns $5 \mu \mathrm{m} 25 \mathrm{~cm} \times 4.6 \mathrm{~mm}$; elution: A/B (70/30) with $0.05 \%$ anhydrous trifluoroacetic acid (TFA) at $1.0 \mathrm{ml} / \mathrm{min}$; A: $0.1 \% \mathrm{H}_{3} \mathrm{PO}_{4}$ in deionized $\mathrm{H}_{2} \mathrm{O} ; \mathrm{B}: 1.4 \mathrm{mg}$ sodium dodecylsulfate/ml acetonitril. Spectral profiling (Diod Array Detector series 200 HP) demonstrated that the small peak corresponding to creatine in the samples was heterogeneous. The values reported for creatine in the results section correspond to highest possible estimates including a probable overestimation. Creatinine was detected according to another modified method (Dash and Sawhney 2002) using the same columns as for creatine but a different elution: ammonium sulfate $5.95 \mathrm{~g} / \mathrm{l}$ deionized $\mathrm{H}_{2} \mathrm{O}$ at $1.0 \mathrm{ml} / \mathrm{min}$. Due to the nature of the elution solvent and the small size of the creatinine peak, its spectral profile could not be obtained. As for creatine, the reported values correspond to highest possible estimates.

\section{Pharmacokinetics}

Using a Marquardt algorithm, all kinetics were fitted with the following equation:

$$
\begin{aligned}
C= & \left(F D / V \times\left(k_{\mathrm{a}} /\left(k_{\mathrm{a}}-k_{\mathrm{el}}\right)\right) \times\left(\exp \left(-k_{\mathrm{el}} \times\left(t-t_{\mathrm{lag}}\right)\right)\right.\right. \\
& \left.\left.-\exp \left(-k_{\mathrm{a}} \times\left(t-t_{\mathrm{lag}}\right)\right)\right)\right)
\end{aligned}
$$

where $C$ is the plasma creatine concentration minus the basal concentration ( $\mu \mathrm{M}$; if $C \leq 0$, then data were removed); $F$ is the bioavailability; $D$ is the dose ( $2 \mathrm{~g}$ or $15300 \mu \mathrm{mol}) ; V$ is 
the volume of distribution; $k_{\mathrm{a}}$ is the velocity constant of absorption (first order, $\mathrm{h}^{-1}$ ); $k_{\mathrm{el}}$ is the velocity constant of elimination (first order, $\mathrm{h}^{-1}$ ); $t$ is the time (h); $t_{\mathrm{lag}}$ is the lagtime (h); No weight was applied to data (weight $=1$ ) and the initial parameters values were estimated using a Simplex algorithm. This equation corresponds to a one-open compartmental model in which $k_{\mathrm{a}}, k_{\mathrm{el}}$ and $t_{\mathrm{lag}}$ are the primary parameters. Knowing their value, new kinetic parameters of plasma creatine were calculated. $\mathrm{AUC}_{0, \infty}$ is the area under the curve integrated from zero to infinity. Since the bioavailability $(F)$ may not be measured, only the apparent volume of distribution and the apparent clearance can be estimated. $V_{\mathrm{d}}$ is the apparent volume of distribution, $V_{\mathrm{d}}=V /$ $F(\mathrm{l})$ and $\mathrm{Cl}$ is the apparent clearance, $\mathrm{Cl}=k_{\mathrm{el}} V_{\mathrm{d}}\left(\mathrm{l} \mathrm{h}^{-1}\right)$

\section{Statistics}

Results are presented as the means \pm standard errors of the means (SEM). Differences between mean values of variables measured with the three forms of creatine ingestion (AS/BG/PP) were assessed by a mixed model representing the order of the treatments (first, second or third treatment) and when applicable, the time of measurement (pre- and post-treatment). When the variable tested was not affected by the order, either a one-way (single dose) or a two-way ANOVA (multiple doses) for repeated measures was used. When a one-way ANOVA was used, the Dunnett test was used as post hoc test to compare BG and PP with AS as the reference treatment. In the case of a two-way ANOVA, the Bonferroni test was applied as post hoc test to compare preand post-treatment conditions. Statistical significance of changes observed in frequencies of discrete variables was inferred by means of a Fisher-test. The significant threshold was set at $P<0.05$.

\section{Results}

Kinetics after a single dose

\section{Urines}

In basal conditions, $24 \mathrm{~h}$ urinary excretion of creatine was $2 \pm 1.9 \mathrm{mg}$. When a single dose of $2 \mathrm{~g}$ creatine was

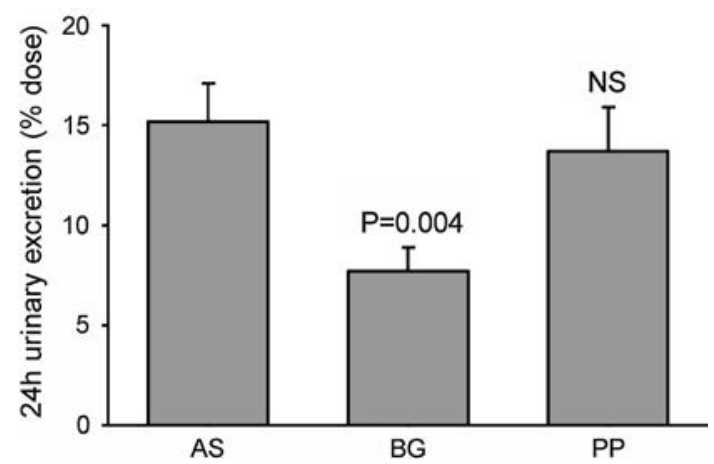

Fig. 2 Percentage of initial dose of creatine $(2 \mathrm{~g})$ excreted in urines in $24 \mathrm{~h}$. Creatine was ingested as an aqueous solution (AS), or incorporated in a beta-glucan- $(\mathrm{BG})$ or protein- $(\mathrm{PP})$ rich food bar. $P$ values above histograms depict statistical significances of differences with AS treatment

consumed in the form of AS and PP, $15 \pm 1.9 \%$ and $14 \pm 2.2 \%$ of the dose, respectively, was found in urine collected during the first $24 \mathrm{~h}$ after ingestion (Fig. 2). Less creatine was excreted after the BG treatment $(8 \pm 1.2 \%$, $P=0.004)$, as compared to AS and PP forms. Most of the excreted creatine appeared in urine during the first $2 \mathrm{~h}$ following intake of AS (Table 1). After $4 \mathrm{~h}$, creatine excretion values became similar to basal conditions.

Creatinine urinary excretion was slightly less than $1 \mathrm{~g} /$ $24 \mathrm{~h}$ and not affected by ingestion of $2 \mathrm{~g}$ creatine whatever the form of ingestion.

Neither creatine, nor creatinine excretions were affected by the order of the treatment.

\section{Plasma concentrations}

The mean basal plasma creatine concentration was $10 \pm 1.0 \mu \mathrm{M}$ (Fig. 3). After ingestion of $2 \mathrm{~g}$ creatine in the form of AS, plasma concentration increased sharply to reach a peak $(299 \pm 19.5 \mu \mathrm{M})$ in less than $1 \mathrm{~h}$ (Table 2$)$. When the same amount of creatine was consumed as a bar, plasma concentration increase was slower; maximal plasma concentration was lower and delayed (Table 2). ANOVA design for repeated measures applied to the kinetic data showed a significant interaction between time and treatments

Table 1 Creatine urinary excretion

\begin{tabular}{lllll}
\hline & $0-2 \mathrm{~h}$ & $2-4 \mathrm{~h}$ & $4-8 \mathrm{~h}$ & $8-24 \mathrm{~h}$ \\
\hline AS & $0.193 \pm 0.0204$ & $0.107 \pm 0.0217$ & $0.002 \pm 0.0010$ & $0.001 \pm 0.0001$ \\
BG & $0.035 \pm 0.0087 * * *$ & $0.108 \pm 0.0195$ & $0.010 \pm 0.0051$ & $0.001 \pm 0.0003$ \\
PP & $0.152 \pm 0.0250$ & $0.117 \pm 0.0223$ & $0.004 \pm 0.0022$ & $0.002 \pm 0.0009$ \\
\hline
\end{tabular}

Urinary creatine excretion ( $\mathrm{g}$ ) during the first $2 \mathrm{~h}$, between the 2 nd and the 4th hour, between the 4 th and the 8 th hour and between the 8 th and the 24th hour after ingestion of $2 \mathrm{~g}$ creatine under the form of an aqueous solution (AS), or incorporated in a beta-glucan- (BG) or protein- (PP) rich food bar. Results are expressed as the means \pm SEM $(n=17)$. ***P $<0.001$ versus AS treatment 


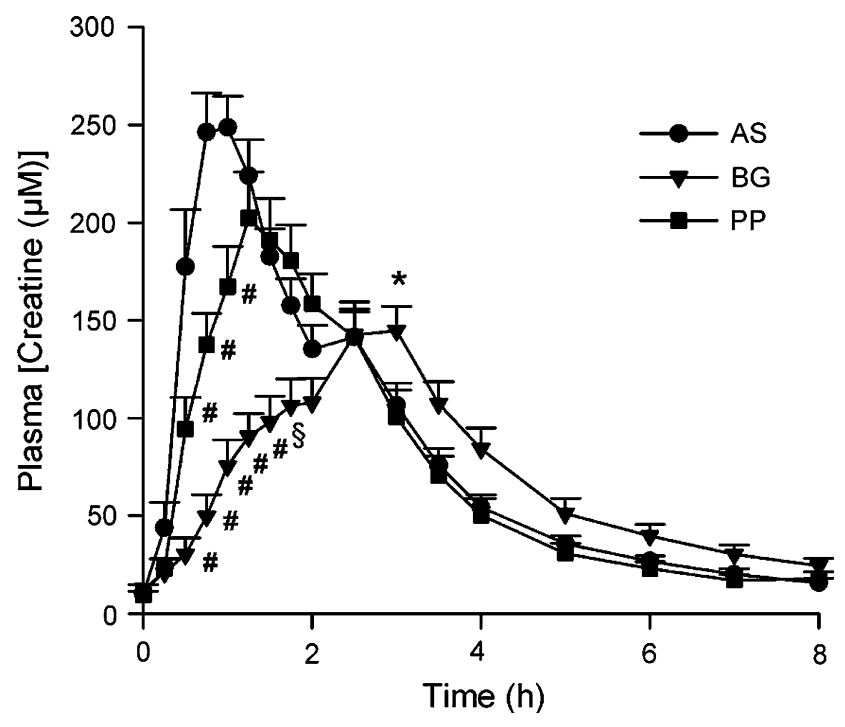

Fig. 3 Kinetics of plasma creatine after an ingestion of $2 \mathrm{~g}$ creatine. The results are expressed as the means \pm SEM $(n=17) . * P<0.05$, $\# P<0.01, \S P<0.001$ versus AS treatment same time

$(P<0.001)$ indicating different time-courses according to the ingested forms (AS/BG/PP). Post hoc analyses showed that the difference emerged during the absorption phase before the peak concentrations were reached (Fig. 3). The peak creatine concentration was lower with $\mathrm{BG}$ $(174 \pm 14.0 \mu \mathrm{M})$ than with PP $(237 \pm 22.3 \mu \mathrm{M}, P=0.019)$ and the peak concentration appeared later $(2.40 \pm 0.177 \mathrm{~h}$ with BG vs. $1.31 \pm 0.150$ h with PP, $P<0.001)$.

The one-open compartment model described by Eq. 1 yielded the best fitting of the plasma creatine time-course (Fig. 4). Other tested models did not allow the algorithm converging or gave larger residuals. Using Eq. 1, the median value of residuals was $1.06 \mu \mathrm{M}$ in AS condition. The first and the third quartiles were -8.90 and $9.97 \mu \mathrm{M}$, respectively. The distributions of residuals were not different in BG and PP conditions where the medians were $-0.49 \mu \mathrm{M}(25 \%$, $-10.04 \mu \mathrm{M}$ to $75 \%, 8.67 \mu \mathrm{M})$ and $0.04 \mu \mathrm{M} \quad(25 \%$, $-10.13 \mu \mathrm{M}$ to $75 \%, 7.98 \mu \mathrm{M})$, respectively. The relationships between observed and calculated plasma creatine concentrations were linear and explained a high fraction of variances: $96 \%$ in $\mathrm{AS} ; 88 \%$ in $\mathrm{BG}$; and $95 \%$ in PP condition.

The lag-time $\left(t_{\text {lag }}\right)$, the velocity constant of elimination $\left(k_{\mathrm{el}}\right)$ and the velocity constant of absorption $\left(k_{\mathrm{a}}\right)$ are the three calculated parameters of Eq. 1. The mixed model analysis did not reveal any effect of the order by which the treatment were given to the subjects, as far as $t_{\mathrm{lag}}, k_{\mathrm{el}}$ and $k_{\mathrm{a}}$ mean values are concerned.

The lag-time $\left(t_{\mathrm{lag}}\right)$ corresponds to the time necessary to observe a change in plasma creatine concentration after the bolus ingestion. When creatine was ingested under AS and $\mathrm{PP}$ forms, the $t_{\mathrm{lag}}$ appeared $0.38 \pm 0.033 \mathrm{~h}$ and $0.43 \pm$ $0.060 \mathrm{~h}$, respectively $(P=\mathrm{NS})$, but $t_{\text {lag }}$ doubled when creatine was ingested as a BG bar $(0.78 \pm 0.114 \mathrm{~h}$, $P<0.001$, Table 2)

The velocity constant of absorption $\left(k_{\mathrm{a}}\right)$ was faster when creatine was ingested under the form of AS in comparison with the bars $(P<0.001$, Table 2$)$. The time of absorption (Tabs) is inversely related to $k_{\mathrm{a}}$. Tabs was $0.55 \pm 0.150 \mathrm{~h}$ in AS condition, whereas it reached $2.18 \pm 0.385 \mathrm{~h}$ in PP $(P<$ $0.001)$ and $4.67 \pm 0.267 \mathrm{~h}$ in $\mathrm{BG}$ condition $(P<0.001)$.

The mean half-life of elimination was $1.09 \pm 0.060 \mathrm{~h}$. Neither the velocity constant of elimination, nor the apparent clearance was affected by the form of creatine ingested (Table 2). The apparent volume of distribution was about $75 \%$ of body mass and was not influenced by the form of creatine ingested (Table 2). The areas under the curve calculated by integration of Eq. 1 from 0 to infinity $\left(\mathrm{AUC}_{0, \infty}\right)$ were identical for all creatine forms (mean value: $539 \pm 30.4 \mu \mathrm{M}$ h, Table 2).

Table 2 also presents the results of the subgroup of subjects $(n=7)$ receiving AS as first treatment.

Mean value of plasma creatinine concentrations in basal condition was $53.5 \pm 1.50 \mu \mathrm{M}$. It changed by only a few $\mu \mathrm{M}$ during the $8 \mathrm{~h}$ following ingestion of creatine independently of the treatment.

Table 2 Plasma kinetic data

\begin{tabular}{lcccc}
\hline & First trial AS $(n=7)$ & AS $(n=17)$ & BG $(n=17)$ & PP $(n=17)$ \\
\hline Peak concentration of plasma creatine (observed, $\mu \mathrm{M})$ & $312 \pm 41.5$ & $299 \pm 19.5$ & $174 \pm 14.0^{* * *}$ & $237 \pm 22.3^{*}$ \\
Time to peak concentration (observed, $\mathrm{h})$ & $0.86 \pm 0.092$ & $0.81 \pm 0.050$ & $2.40 \pm 0.177^{* * *}$ & $1.31 \pm 0.146^{*}$ \\
Lag-time $(\mathrm{h})$ & $0.42 \pm 0.060$ & $0.38 \pm 0.033$ & $0.78 \pm 0.114^{* * *}$ & $0.43 \pm 0.060$ \\
Velocity constant of absorption $\left(\mathrm{h}^{-1}\right)$ & $25.44 \pm 8.780$ & $23.63 \pm 6.655$ & $0.78 \pm 0.045^{* * *}$ & $4.58 \pm 7.050^{* *}$ \\
Time of absorption $(\mathrm{h})$ & $0.34 \pm 0.102$ & $0.55 \pm 0.150$ & $4.67 \pm 0.267^{* * *}$ & $2.18 \pm 0.385^{* * *}$ \\
Velocity constant of elimination $\left(\mathrm{h}^{-1}\right)$ & $0.79 \pm 0.111$ & $0.68 \pm 0.058$ & $0.71 \pm 0.056$ & $0.74 \pm 0.056$ \\
Area under the curve $(0 \rightarrow \infty, \mu \mathrm{M} \mathrm{h})$ & $511 \pm 86.5$ & $587 \pm 56.2$ & $501 \pm 44.9$ & $528 \pm 57.0$ \\
Apparent volume of distribution $(\mathrm{l})$ & $49.4 \pm 8.51$ & $47.1 \pm 4.16$ & $55.5 \pm 8.88$ & $60.6 \pm 14.68$ \\
Apparent clearance $\left(1 \mathrm{~h}^{-1}\right)$ & $42.6 \pm 14.01$ & $33.7 \pm 6.22$ & $35.4 \pm 3.87$ & $38.9 \pm 6.70$ \\
\hline
\end{tabular}

Plasma kinetic data after an ingestion of $2 \mathrm{~g}$ creatine. $A S$ aqueous solution, $B G$ beta-glucan-rich bar, $P P$ protein-rich bar. First trial AS reports results of subjects receiving AS as first treatment. The results are expressed as the means \pm SEM. $* P<0.05$, $* * * P<0.001$ versus AS treatment 

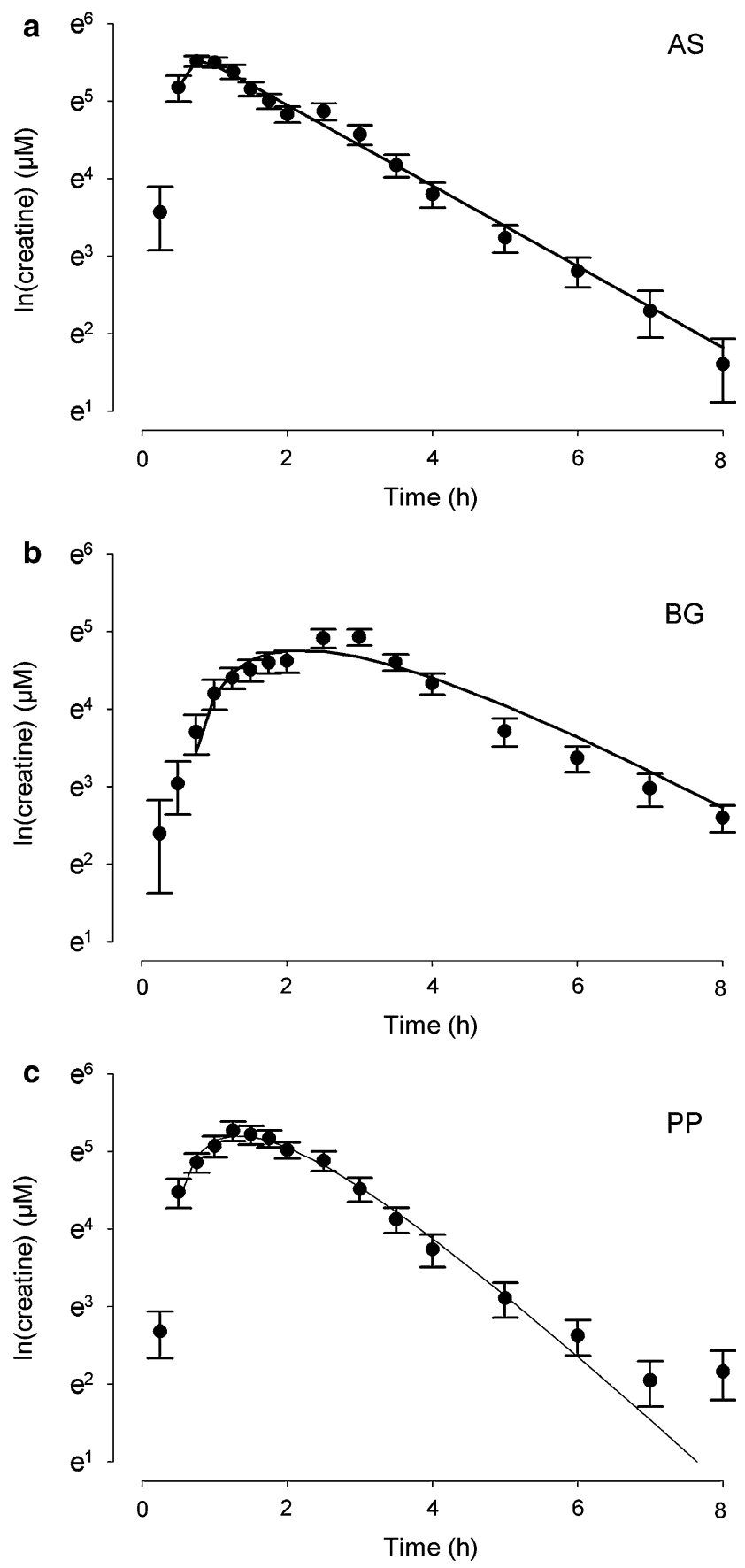

Fig. 4 Kinetics of plasma creatine after an ingestion of $2 \mathrm{~g}$ creatine. The fitted curve is given by Eq. 1 (see "Materials and methods"). $A S$ aqueous solution, $B G$ beta-glucan-rich bar, $P P$ protein-rich bar. The results are expressed as the means $\pm \operatorname{SEM}(n=17)$

Ingestion of multiple doses

\section{Body mass}

Body mass was affected by the order of the treatments demonstrating a progressive increase in body mass across the trials $(P<0.001)$. The mean body mass values were
$68.2 \pm 1.45 \mathrm{~kg}$ before the first trial, $68.8 \pm 1.49 \mathrm{~kg}$ before the second trial and $69.7 \pm 1.54 \mathrm{~kg}$ before the third one. Considering the factor "order", the mixed model was unable to demonstrate any further changes in body mass in whatever the form the creatine was ingested (Table 3).

Considering that the progressive increase in body mass observed during the whole period of experimentation might be due to the energy contained in the bars, the order factor was replaced in the mixed model by a carry-over factor, i.e. a factor representing the previous treatment (AS/BG/PP). Indeed, AS treatment only provided a negligible amount of energy compared to BG and PP bars and therefore, one could hypothesize that PP and BG treatments induced changes in body mass whereas AS does not. The results of the statistical analysis did not show a significant carry-over effect suggesting that the form of the previous treatment had no influence on body mass during the subsequent trial. Therefore, the increase in body mass following the first treatment was most probably due to the ingestion of creatine. As observed for plasma creatinine (see below), the increase in body mass suggests that the period between treatments was too short to enable baseline creatine levels to be attained. Nevertheless, due to the design of the study this would not invalidate the main conclusions.

\section{Plasma concentrations}

After 1 week of creatine supplementation, plasma creatine and creatinine concentrations were measured again in a fasted state. Plasma creatine concentration, the value of which was not influenced by the order of the treatments, was $11 \pm 2.5$-fold higher after supplementation (Fig. 5a). The increase after PP creatine form was lower $(+30 \pm 5.2 \mu \mathrm{M})$ than after AS and BG supplementation (+86 $\pm 33.5 \mu \mathrm{M}$ and $+85 \pm 14.3 \mu \mathrm{M}$, respectively), with a significant interaction between treatments (AS/BG/PP) and conditions (pre-/post-supplementation). There was a significant order effect for creatinine plasma concentration $(P<0.001)$. The basal mean values were $49.0 \pm 2.22 \mu \mathrm{M}$, $54.7 \pm 3.30 \mu \mathrm{M}$ and $56.8 \pm 1.83 \mathrm{~kg}$ for the first, second

Table 3 Body mass

\begin{tabular}{lll}
\hline & Before & After \\
\hline AS & $68.9 \pm 1.53$ & $69.2 \pm 1.56$ \\
BG & $69.1 \pm 1.53$ & $69.6 \pm 1.54$ \\
PP & $69.0 \pm 1.43$ & $69.8 \pm 1.50$ \\
\hline
\end{tabular}

Body mass $(\mathrm{kg})$ before and after 1 week creatine supplementation $(3 \times 2 \mathrm{~g}$ per day). Creatine was administered under the form of an aqueous solution (AS), or incorporated in a beta-glucan- (BG) or protein- (PP) rich food bar. Results are expressed as the means \pm $\operatorname{SEM}(n=17)$ 
and third trial, respectively. Despite the progressive increase in the basal concentration over the time of the experimentation, 1-week creatine supplementation slightly increased plasma creatinine concentrations by all treatments $(P<0.05)$, independently of the form of the ingested creatine form (Fig. 5b).

\section{Erythrocyte concentrations}

Erythrocyte creatine concentration showed large interindividual differences as illustrated by a coefficient of variation of basal values of $59 \%$, but was not influenced by the order of treatments. It was increased by $88 \pm 22 \%$ after creatine supplementation independently of the form of ingested creatine (Fig. 6). There was no significant interaction between treatment (AS/BG/PP) and condition (pre-/ post-) indicating that the form of creatine ingested had no further influence on the erythrocyte creatine level.
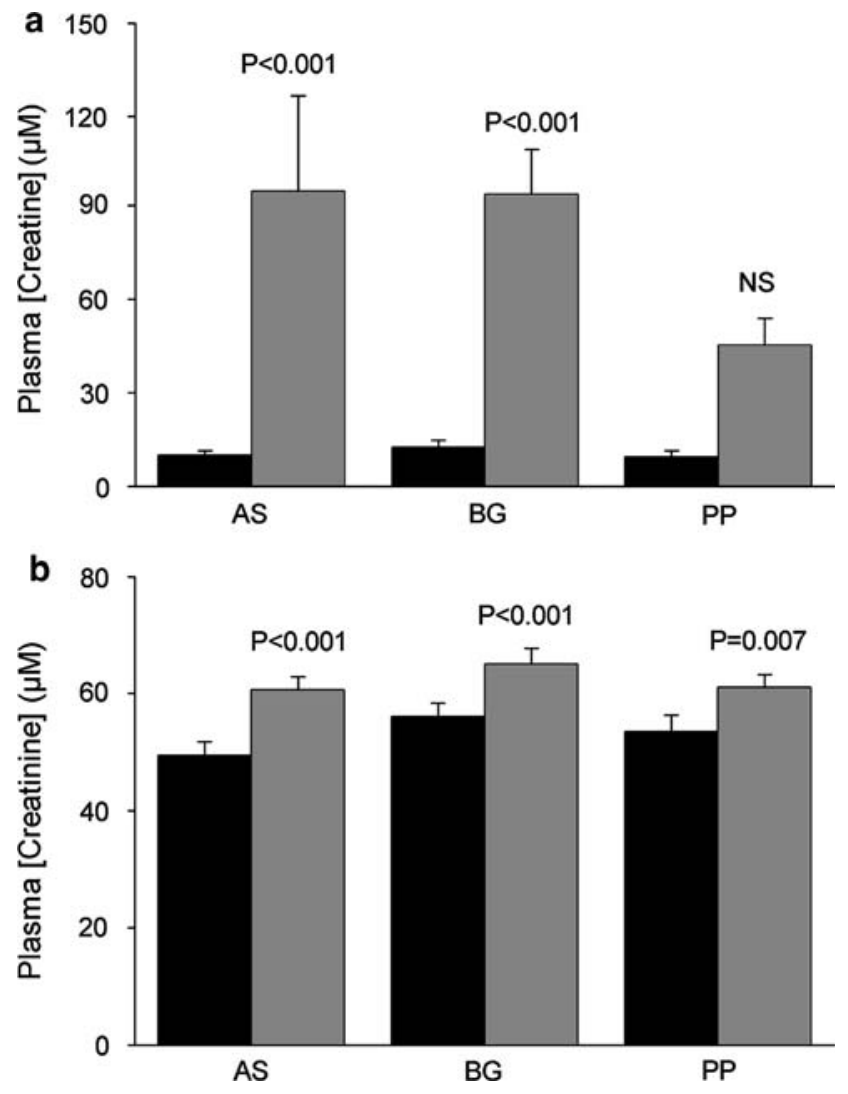

Fig. 5 Plasma creatine a and creatinine b concentrations measured before (black) and after 1 week (grey) creatine supplementation $(3 \times 2 \mathrm{~g}$ per day). $P$ values above histograms depict statistical significances of differences between pre- and post- creatine supplementation. $A S$ aqueous solution, $B G$ beta-glucan-rich bar, $P P$ proteinrich bar. The results are expressed as the means $\pm \operatorname{SEM}(n=17)$
Basal erythrocyte creatinine concentration was about $25 \mu \mathrm{M}$ and remained stable throughout the entire experiment.

\section{Feces}

Whatever the conditions, basal or supplemented, creatine and creatinine could not be quantified in human feces. The methods used were sufficiently sensitive to indicate that the maximal estimated value was $\sim 15 \pm 1.2 \mu \mathrm{g} / \mathrm{g}$ fresh feces for creatinine and $\sim 50 \pm 5.7 \mu \mathrm{g} / \mathrm{g}$ fresh feces for creatine.

\section{Side effects}

During the initial visit and after each period of creatine supplementation, all subjects filled in a questionnaire listing potential side effects. No difference was observed in the frequency of declared health troubles except for muscle cramps, which were less frequently reported after creatine supplementation $(P<0.05)$.

\section{Discussion}

Although creatine is widely used as a dietary supplement, only few studies aimed to describe its pharmacokinetics (Fitch and Sinton 1964; Green et al. 1996; Harris et al. 1992; Schedel et al. 1999; Vanakoski et al. 1998). After ingestion of a single low dose, the time-course of plasma concentration is generally accepted to follow a one-open compartment model with first-order absorption and elimination constants (Persky et al. 2003). The results of the

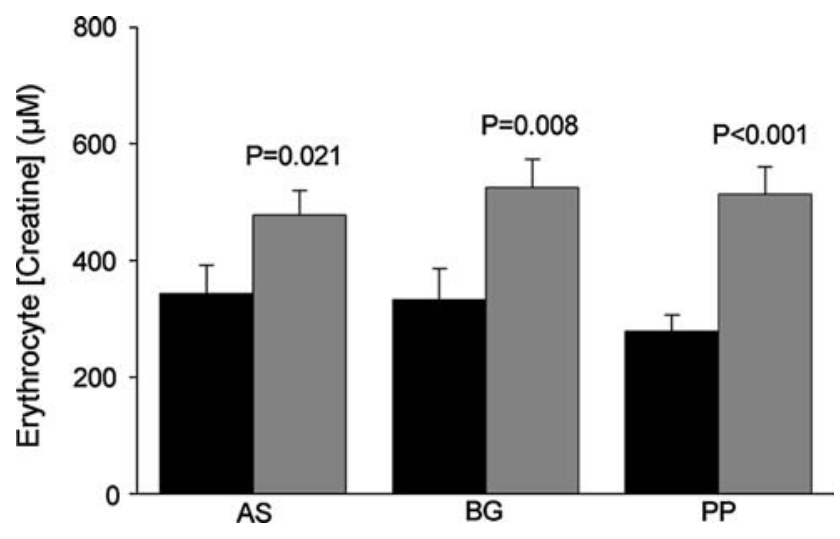

Fig. 6 Erythrocyte creatine concentration measured before (black) and after 1 week (grey) creatine supplementation $(3 \times 2$ g per day). $P$ values above histograms depict statistical significances of differences between pre- and post- creatine supplementation. $A S$ aqueous solution, $B G$ beta-glucan-rich bar, $P P$ protein-rich bar. The results are expressed as the means $\pm \operatorname{SEM}(n=17)$ 
present study support this statement. Models with a zeroorder constant of absorption and with a bi-exponential elimination phase were tested and yielded unsatisfying fittings.

Once ingested, creatine has potentially various fates. Due to the low $\mathrm{pH}$ in the stomach, it could be transformed in creatinine. However, the rate of conversion is rather slow (Cannan and Shore 1928). The half-lives of degradation are 55, 7.5 and 40.5 days at $\mathrm{pH}$ values $1.4,3.7$ and 6.8 , respectively (Chanutin, 1926). Thus, considering a $\mathrm{pH}$ of stomach near to 2 and a dose of $2 \mathrm{~g}$, only $1 \%$ of this amount would be converted to creatinine within the first hour after ingestion. This rate of creatine degradation is in the same range in the intestinal tract $(\mathrm{pH}=6-7)$. As creatine remains a longer period of time in the intestine than in the stomach, it is likely to be degraded in a larger proportion at this level. However, the stable plasma creatinine concentration following ingestion of creatine, in addition to its undetectable amount in feces, corroborate the hypothesis that the conversion of creatine to creatinine remains negligible in the gastrointestinal tract.

Under conditions that exist in stomach, creatine can theoretically be converted to $N$-nitrososarcosine (Archer et al. 1971). Creatine can also be degraded to sarcosine by microbial reactions (Wyss and Kaddurah-Daouk 2000) and therefore, give rise to intestinal methylamine and formaldehyde. Experimental protocols carried out in humans ingesting large amounts of creatine did not reveal any increase in urinary nitrosarcosine (Derave et al. 2006), but reported a higher excretion of methylamine and formaldehyde, although the latter remained within a normal range (Poortmans et al. 2005). To the best of our knowledge, no publications have yet reported the presence of $N$-nitrososarcosine, methylamine or formaldehyde in feces. Even if these substances might be potentially toxic, such transformations are quantitatively negligible and the bulk of creatine ingested remains available for absorption.

In the pharmacokinetic model, the lag-time represents the time between creatine ingestion and the onset of the rise in plasma concentration. The lag-time was $0.38 \pm 0.033$ and $0.43 \pm 0.060 \mathrm{~h}$ after ingestion of creatine in fasted state under AS and PP forms, respectively, but was doubled with BG-rich bar $(0.78 \pm 0.114 \mathrm{~h}, P<0.001)$. This indicates that the presence of BG in the meal slows down the velocity of transit probably by increasing the viscosity of the bolus (Wursch and Pi-Sunyer 1997).

Once in the small intestine, creatine is taken up by an active, saturable end electrogenic $\mathrm{Na}^{+}: \mathrm{Cl}^{-}$cotransporter located at the brush-border membrane (Peral et al. 2002). This protein is a member of the superfamily of $\mathrm{Na}^{+}: \mathrm{Cl}^{-}$ dependent transporters responsible for the uptake of certain amino acids (e.g., glycine and proline) and other molecules like dopamine, GABA, serotonin, taurine and betaine
(Guimbal and Kilimann 1994; Nelson and Lill 1994). Experiments using these substances revealed a high specificity of the creatine transporter $\left(K_{\mathrm{m}}=29 \mu \mathrm{M}\right.$; Peral et al. 2002). The fact that the kinetics of plasma creatine corresponds to a first-order model suggests that the transporter is not saturated by a single dose of $2 \mathrm{~g}$ creatine.

The velocity constant of creatine absorption was slower when incorporated in a PP-rich bar $\left(4.58 \pm 7.050 \mathrm{~h}^{-1}\right)$ as compared to AS form $\left(23.63 \pm 6.655 \mathrm{~h}^{-1}, P<0.01\right)$. Due to the high specificity of the creatine transporter in the small intestine (Peral et al. 2002), the slower rate of absorption cannot be explained by a competition with amino acids. The presence of a bolus in the gastrointestinal tract diminishes the rate of absorption of drugs (Welling 1977). It seems that the same phenomenon could occur with creatine. Moreover, BG are viscous polysaccharides that result in a slower rate of carbohydrate and lipid absorption when included in a meal (Lifschitz et al. 2002). This property of BG makes the rate of absorption even slower and cannot be explained by the presence of the bolus alone (Bonferroni-test $\mathrm{PP}$ vs. BG, $P<0.05$ ). Therefore, the results of the present study also reveal that $\mathrm{BG}$ form reduces the absorption rate of substances other than carbohydrates and lipids.

Bioavailability $(F)$ did not seem to be affected by the form of ingested creatine since the AUC integrated from zero to infinity were not different. This observation contradicts the findings of an altered bioavailability when creatine is ingested as a lozenge or in suspension (Harris et al. 2002). The results of the latter study were discussed by Persky et al (2003) who pointed out that AUC was integrated from 0 to $6 \mathrm{~h}$, whereas integration to infinity is necessary to assess the pertinence of bioequivalence.

As mentioned, the transformation in gastrointestinal tract of creatine into other compounds is quantitatively low compared to the transit duration. We did not find detectable amount of creatine in the feces after 1 week creatine supplementation $(3 \times 2 \mathrm{~g} /$ day $)$ indicating that creatine is completely absorbed. There is no reason to believe that creatine would be taken up first by the liver and therefore, most of the creatine ingested would appear in arterial blood. However, creatine is obviously taken up by different cells (e.g., muscles, erythrocytes, etc.) before reaching venous blood. Thus, it is likely that the arterial bioavailability nearly reaches $100 \%$, whereas it will be lesser at the venous level. Since $V_{\mathrm{d}}=V / F$ (see above), it sounds reasonable to find an apparent larger volume of distribution $\left(V_{\mathrm{d}}\right)$ as compared to the extracellular space (Table 2).

Previous studies reported that a large proportion of creatine ingested (40-72\%) is excreted in urine (Poortmans and Francaux 2007). Figure 2 shows that this proportion can be reduced to about $15 \%$ by giving smaller amount of creatine (namely $2 \mathrm{~g}$ ). 
The half-life of elimination is about $1 \mathrm{~h}$ whatever form the creatine was ingested. Considering the low rate of metabolic degradation of creatine (see above), the amount appearing in blood is either eliminated in urine or taken up by the tissues. Since the AUC is not different between treatments, it may be assumed that the amount of creatine appearing in blood remains similar. Therefore, the lower urinary excretion in BG than in AS implies a larger uptake by tissues. This difference appears within the first $2 \mathrm{~h}$ after creatine ingestion (Table 1) and is likely due to a slower absorption rate with $\mathrm{BG}$, which results in a lower and delayed plasma peak concentration (Table 2). Although, PP had similar effects, it does not reduce the absorption rate sufficiently enough to modify the urinary excretion of creatine.

In this study, the pharmacokinetics after multiple doses has not been investigated. Evidence suggests that the absorption of creatine is saturable and therefore that its kinetics is nonlinear in such conditions with respect to dose size and frequency (for review, see Persky et al. 2003). On the other hand, tissues such as skeletal muscle have a limited capacity to accumulate creatine (Harris et al. 1992) and the saturation of these stores could potentially affect the value of the velocity constant of elimination. Therefore, the model of Eq. 1 and the parameters values presented in Table 2 are certainly not suitable for a regimen of multiple doses. After 1-week supplementation (6 g/day) and one night fast, plasma creatine concentration remained significantly elevated in AS and BG conditions, but the statistical threshold was not reached with PP due to the large interindividual variability. Lack of compliance could be evoked to explain this result. But since the erythrocyte content increased similarly in the three conditions (Fig. 6), this hypothesis is unlikely. Actually, we have no arguments which can explain this observation.

Several publications investigated the creatinine excretion rate after ingestion of repeated doses of creatine. Some showed an increase in creatinine excretion (Crim et al. 1975; Hultman et al. 1996), while others did not observe any changes after short-term (Maganaris and Maughan 1998), medium-term (Vandenberghe et al. 1997) or longterm (Poortmans and Francaux 1999) oral creatine supplementation. In the present study, the daily ingestion of three doses of $2 \mathrm{~g}$ creatine, slightly but significantly increased plasma creatinine concentration after 1 week independently of the form of the treatment (Fig. 5b). Although, renal clearance of creatinine was not measured, it is unlikely that this change reveals a drop in glomerular filtration rate. In most kidney diseases, plasma creatinine levels are much higher than the normal upper range limit of $1.5 \mathrm{mg} \%(\sim 130 \mu \mathrm{M})$. The present values are largely below this level (Fig. 5b). Moreover, our previous investigations never observed any changes in the glomerular filtration rate, expressed by the creatinine clearance (Poortmans and Francaux 1999, 2002). Creatine stored in tissues is degraded by a non-enzymatic reaction into creatinine. Therefore, a higher creatine concentration in tissues induces a higher creatinine production according to the mass action law and its diffusion to the plasma.

Although the washout period was $40 \pm 1.2$ days, the first and the second supplementation periods increased slightly but significantly the plasma creatinine concentrations measured during the subsequent trial $(P<0.001)$. This suggests that certain tissues (e.g., the muscle) still release a higher than basal amounts of creatinine at the time the next trial began. Given the nature of the conversion of creatine to creatinine (non enzymatic, first order, $1.67 \%$ per day), the whole body creatine content did not regain the basal level prior to the second and the third treatments. Although there is no statistical differences in the $k_{\mathrm{el}}$ values measured during the first, second and third trial, the more reliable measurements of elimination are those gained following the first treatment where $k_{\mathrm{el}}=$ $0.78 \pm 0.063 \mathrm{~h}^{-1}$ (Table 2).

Basal values of erythrocyte creatine concentrations reported in the present study are in the same range as those reported by other authors (Buysse et al. 1990; Jiao et al. 1998; Preen et al. 2005). After supplementation, it increased independently of the form of the treatment to reach approximately $500 \mu \mathrm{M}(+88 \%$, Fig. 6) confirming that creatine is taken up by the erythrocytes. Accretion seems dose-dependent since supplementation of $20 \mathrm{~g}$ a day for 5 days leads to a $130 \pm 30 \%$ increase of creatine in erythrocytes (Preen et al. 2005).

A side effect of oral creatine supplementation regularly mentioned by consumers is the increase in body mass (Francaux and Poortmans 2006). In the present experiment, changes in body mass due to creatine were not specifically assessed. Nevertheless, it is possible that this often reported effect was blunted by the progressive increase in body mass observed during the experimentation (3-4 months by subjects). This increase might be due to (1) a washout period which did not allow a complete recovery of body mass after creatine supplementation, (2) the energy contained in the bars and (3) an undetermined cause of body mass increase. The statistical analysis including a carryover factor ruled out the second hypothesis. Since the protocol did not include a placebo group, we were not able to distinguish between the first and the third hypothesis.

No deleterious effect of creatine consumption was reported by the subjects whatever form the creatine was ingested. This confirms other studies summarized in Francaux and Poortmans (2006). The higher occurrence of muscle cramps in basal conditions is probably due to a bias related to the level of physical activity during the week preceding the first visit. 
Ingestion of a single-dose of creatine $(2 \mathrm{~g})$ combined with BG facilitates its retention by slowing down the absorption rate and its urinary excretion. The present study demonstrates clearly that gastrointestinal absorption is complete, without any fecal waste, during a multiple-dose supplementation $(3 \times 2 \mathrm{~g} /$ day for 7 days $)$. During such protocol, the erythrocyte creatine content increases markedly, though there was no evidence that the form of the ingested creatine made a difference. Future studies might look at muscle creatine.

Acknowledgments The authors are indebted to Francine LoupeReding and Vinciane Godaert for their technical assistance, Dominik Grathwohl for his assistance in the statistical treatment of the data and Antoine Audrin, Aylin Harzadin and Jean-Jacques Desjardins for recipes and manufacture of the test bars.

\section{References}

Archer MC, Clark SD, Thilly JE, Tannenbaum SR (1971) Environmental nitroso compounds: reaction of nitrite with creatine and creatinine. Science 174:1341-1343

Balsom PD, Soderlund K, Sjodin B, Ekblom B (1995) Skeletal muscle metabolism during short duration high-intensity exercise: influence of creatine supplementation. Acta Physiol Scand 154:303-310

Buysse AM, Delanghe JR, De Buyzere ML, De Scheerder IK, De Mol AM, Noens L (1990) Enzymatic erythrocyte creatine determinations as an index for cell age. Clin Chim Acta 187:155-162

Cannan RK, Shore A (1928) The creatine-creatinine equilibrium. The apparent dissociation constants of creatine and creatinine. Biochem J 22:920-929

Chanutin A (1926) The fate of creatine when administered to man. J Biol Chem: 29-41

Crim MC, Calloway DH, Margen S (1975) Creatine metabolism in men: urinary creatine and creatinine excretions with creatine feeding. J Nutr 105:428-438

Dash AK, Sawhney A (2002) A simple LC method with UV detection for the analysis of creatine and creatinine and its application to several creatine formulations. J Pharm Biomed Anal 29:939-945

Dechent P, Pouwels PJ, Wilken B, Hanefeld F, Frahm J (1999) Increase of total creatine in human brain after oral supplementation of creatine-monohydrate. Am J Physiol 277:R698R704

Deldicque L, Louis M, Theisen D, Nielens H, Dehoux M, Thissen JP, Rennie MJ, Francaux M (2005) Increased IGF mRNA in human skeletal muscle after creatine supplementation. Med Sci Sports Exerc 37:731-736

Derave W, Vanden Eede E, Hespel P, Carmella SG, Hecht SS (2006) Oral creatine supplementation in humans does not elevate urinary excretion of the carcinogen $\mathrm{N}$-nitrososarcosine. Nutrition 22:332-333

Febbraio M, Flanagan TR, Snow RJ, Zhao S, Carey MF (1995) Effect of creatine supplementation on intramuscular TCr, metabolism and performance during intermittent, supramaximal exercise in humans. Acta Physiol Scand 155:387-395

Fitch CD, Sinton DW (1964) A study of creatine metabolism in diseases causing muscle wasting. J Clin Invest 43:444-452

Folin O (1906) Hammarsten's Festschrift. iii: 1

Francaux M, Poortmans JR (2006) Side sffects of creatine supplementation in athletes. Int J Sports Physiol Perf 1:309-321
Ganguly S, Jayappa S, Dash AK (2003) Evaluation of the stability of creatine in solution prepared from effervescent creatine formulations. AAPS Pharm Sci Tech 4:E25

Green AL, Hultman E, Macdonald IA, Sewell DA, Greenhaff PL (1996) Carbohydrate ingestion augments skeletal muscle creatine accumulation during creatine supplementation in humans. Am J Physiol 271:E821-E826

Greenhaff PL, Bodin K, Soderlund K, Hultman E (1994) Effect of oral creatine supplementation on skeletal muscle phosphocreatine resynthesis. Am J Physiol 266:E725-E730

Guimbal C, Kilimann MW (1994) A creatine transporter cDNA from Torpedo illustrates structure/function relationships in the GABA/ noradrenaline transporter family. J Mol Biol 241:317-324

Harris RC, Soderlund K, Hultman E (1992) Elevation of creatine in resting and exercised muscle of normal subjects by creatine supplementation. Clin Sci (Lond) 83:367-374

Harris RC, Nevill M, Harris DB, Fallowfield JL, Bogdanis GC, Wise JA (2002) Absorption of creatine supplied as a drink, in meat or in solid form. J Sports Sci 20:147-151

Hespel P, Op't Eijnde B, Van Leemputte M, Urso B, Greenhaff PL, Labarque V, Dymarkowski S, Van Hecke P, Richter EA (2001) Oral creatine supplementation facilitates the rehabilitation of disuse atrophy and alters the expression of muscle myogenic factors in humans. J Physiol 536:625-633

Hultman E, Soderlund K, Timmons JA, Cederblad G, Greenhaff PL (1996) Muscle creatine loading in men. J Appl Physiol 81:232-237

Jiao Y, Okumiya T, Saibara T, Tsubosaki E, Matsumura H, Park K, Sugimoto K, Kageoka T, Sasaki M (1998) An enzymatic assay for erythrocyte creatine as an index of the erythrocyte life time. Clin Biochem 31:59-65

Koshy KM, Griswold E, Schneeberger EE (1999) Interstitial nephritis in a patient taking creatine. N Engl J Med 340:814-815

Kreider RB, Ferreira M, Wilson M, Grindstaff P, Plisk S, Reinardy J, Cantler E, Almada AL (1998) Effects of creatine supplementation on body composition, strength, and sprint performance. Med Sci Sports Exerc 30:73-82

Lifschitz CH, Grusak MA, Butte NF (2002) Carbohydrate digestion in humans from a beta-glucan-enriched barley is reduced. J Nutr 132:2593-2596

Louis M, Lebacq J, Poortmans JR, Belpaire-Dethiou MC, Devogelaer JP, Van Hecke P, Goubel F, Francaux M (2003) Beneficial effects of creatine supplementation in dystrophic patients. Muscle Nerve 27:604-610

Maganaris CN, Maughan RJ (1998) Creatine supplementation enhances maximum voluntary isometric force and endurance capacity in resistance trained men. Acta Physiol Scand 163:279_ 287

McMorris T, Harris RC, Howard AN, Langridge G, Hall B, Corbett J, Dicks M, Hodgson C (2007) Creatine supplementation, sleep deprivation, cortisol, melatonin and behavior. Physiol Behav 90:21-28

Nelson N, Lill H (1994) Porters and neurotransmitter transporters. J Exp Biol 196:213-228

Peral MJ, Garcia-Delgado M, Calonge ML, Duran JM, De La Horra MC, Wallimann T, Speer O, Ilundain A (2002) Human, rat and chicken small intestinal $\mathrm{Na}+-\mathrm{Cl}-$-creatine transporter: functional, molecular characterization and localization. J Physiol 545:133-144

Persky AM, Brazeau GA, Hochhaus G (2003) Pharmacokinetics of the dietary supplement creatine. Clin Pharmacokinet 42:557-574

Poortmans JR, Francaux M (1999) Long-term oral creatine supplementation does not impair renal function in healthy athletes. Med Sci Sports Exerc 31:1108-1110

Poortmans JR, Francaux M (2002) Renal implications of exogenous creatine monohydrate supplementation. Am J Med Sports 4:212216 
Poortmans JR, Kumps A, Duez P, Fofonka A, Carpentier A, Francaux M (2005) Effect of oral creatine supplementation on urinary methylamine, formaldehyde, and formate. Med Sci Sports Exerc 37:1717-1720

Poortmans JR, Francaux M (2007) Creatine consumption in health. In: JR Stout (ed) Essentials of creatine in sports (in press)

Preen DB, Dawson BT, Goodman C, Beilby J, Ching S (2005) Comparison of erythrocyte and skeletal muscle creatine accumulation following creatine loading. Int $\mathrm{J}$ Sport Nutr Exerc Metab 15:84-93

Pritchard NR, Kalra PA (1998) Renal dysfunction accompanying oral creatine supplements. Lancet 351:1252-1253

Schedel JM, Tanaka H, Kiyonaga A, Shindo M, Schutz Y (1999) Acute creatine ingestion in human: consequences on serum creatine and creatinine concentrations. Life Sci 65:2463-2470

Siedel J, Mollering H, Ziegenhorn J (1984) Sensitive color reagent for the enzymatic determination of creatinine. Clin Chem 30:968

Tarnopolsky MA, Mahoney DJ, Vajsar J, Rodriguez C, Doherty TJ, Roy BD, Biggar D (2004) Creatine monohydrate enhances strength and body composition in Duchenne muscular dystrophy. Neurology 62:1771-1777
Terjung RL, Clarkson P, Eichner ER, Greenhaff PL, Hespel PJ, Israel RG, Kraemer WJ, Meyer RA, Spriet LL, Tarnopolsky MA, Wagenmakers AJ, Williams MH (2000) American College of Sports Medicine roundtable. The physiological and health effects of oral creatine supplementation. Med Sci Sports Exerc 32:706717

Vanakoski J, Kosunen V, Meririnne E, Seppala T (1998) Creatine and caffeine in anaerobic and aerobic exercise: effects on physical performance and pharmacokinetic considerations. Int J Clin Pharmacol Ther 36:258-262

Vandenberghe K, Goris M, Van Hecke P, Van Leemputte M, Vangerven L, Hespel P (1997) Long-term creatine intake is beneficial to muscle performance during resistance training. $\mathrm{J}$ Appl Physiol 83:2055-2063

Welling PG (1977) Influence of food and diet on gastrointestinal drug absorption: a review. J Pharmacokinet Biopharm 5:291-334

Wursch P, Pi-Sunyer FX (1997) The role of viscous soluble fiber in the metabolic control of diabetes. A review with special emphasis on cereals rich in beta-glucan. Diabetes Care 20:1774-1780

Wyss M, Kaddurah-Daouk R (2000) Creatine and creatinine metabolism. Physiol Rev 80:1107-1213 